\title{
Plasma-Derived miRNA-222 as a Candidate Marker for Papillary Thyroid Cancer
}

\author{
Aistė Kondrotienè ${ }^{1} \mathbb{D}$, Albertas Daukša ${ }^{2}$, Daina Pamedytytè ${ }^{3}$, Mintautè Kazokaitė ${ }^{1}{ }^{1}$, \\ Aurelija Žvirbliene ${ }^{3}$, Dalia Daukšiene ${ }^{1}$, Vaida Simanavičiené ${ }^{3}$, Raimonda Klimaite் ${ }^{1} \mathbb{D}$, \\ Ieva Golubickaite ${ }^{4}{ }^{\oplus}$, Rytis Stakaitis ${ }^{5}{ }^{\circledR}$, Valdas Šarauskas ${ }^{6}$, Rasa Verkauskienè ${ }^{1}$ and \\ Birutė Žilaitiené ${ }^{1, *(1)}$
}

1 Institute of Endocrinology, Medical Academy, Lithuanian University of Health Sciences, LT-50161 Kaunas, Lithuania; aiste.kondrotiene@lsmuni.lt (A.K.); mintaute.kazokaite@lsmuni.lt (M.K.); dalia.dauksiene@lsmu.lt (D.D.); raimonda.klimaite@lsmuni.lt (R.K.); rasa.verkauskiene@lsmuni.lt (R.V.)

2 Institute of Digestive Research, Medical Academy, Faculty of Medicine, Lithuanian University of Health Sciences, LT-50161 Kaunas, Lithuania; albertas.dauksa@lsmuni.lt

3 Institute of Biotechnology, Life Sciences Center, Vilnius University, LT-10257 Vilnius, Lithuania; daina.pamedytyte@gmc.vu.lt (D.P.); aurelija.zvirbliene@bti.vu.lt (A.Ž.); vaida.simanav@gmail.com (V.S.)

4 Institute of Biology systems and genetic research, Lithuanian University of Health Sciences, LT-50161 Kaunas, Lithuania; ieva.golubickaite@lsmuni.lt

5 Laboratory of Molecular Neurooncology, Neuroscience Institute, Lithuanian University of Health Sciences, LT-50161 Kaunas, Lithuania; rytis.stakaitis@1smuni.lt

6 Department of Pathology, Lithuanian University of Health Sciences, LT-50161 Kaunas, Lithuania; valdas.sarauskas@1smuni.lt

* Correspondence: birute.zilaitiene@lsmuni.lt; Tel.: +370-68649882

Received: 30 July 2020; Accepted: 31 August 2020; Published: 3 September 2020

\begin{abstract}
We analyzed five miRNA molecules (miR-221; miR-222; miR-146b; miR-21; miR-181b) in the plasma of patients with papillary thyroid cancer (PTC), nodular goiter (NG) and healthy controls (HC) and evaluated their diagnostic value for differentiation of PTC from NG and HC. Preoperative PTC plasma miRNA expression $(n=49)$ was compared with plasma miRNA in the HC group $(n=57)$ and patients with NG $(n=23)$. It was demonstrated that miR-221; miR-222; miR-146b; miR-21 and miR-181b were overexpressed in preoperative PTC plasma samples compared to HC $(p<0.0001$; $p<0.0001 ; p<0.0001 ; p<0.0001 ; p<0.002$; respectively). The upregulation in tumor tissue of these miRNAs was consistent with The Cancer Genome Atlas Thyroid Carcinoma dataset. A significant decrease in miR-21; miR-221; miR-146b and miR-181b expression was observed in the plasma of PTC patients after total thyroidectomy $(p=0.004 ; p=0.001 ; p=0.03 ; p=0.036$; respectively). The levels of miR-222 were significantly higher in the preoperative PTC compared to the NG group $(p=0.004)$. ROC curve (receiver operating characteristic curve) analysis revealed miR-222 as a potential marker in distinguishing PTC from NG (AUC 0.711; $p=0.004$ ). In conclusion; circulating miR-222 profiles might be useful in discriminating PTC from NG.
\end{abstract}

Keywords: papillary thyroid carcinoma; miR-146b; miR-222; miR-221; miR-21; miR-181b; plasma

\section{Introduction}

Papillary thyroid carcinoma (PTC) is the most common type of thyroid cancer (85\%-90\%) [1]. The 10-year survival rate in PTC after treatment is higher than 90\% [2]. However, regional or distant metastatic recurrences occur in up to $10 \%$ of cases [3]. The current clinical difficulty is in properly identifying PTC cancer. Ultrasound diagnosis depends on the experience and knowledge of the examiner. Fine needle aspiration biopsy (FNAB) also has limitations, as it is quite challenging to take a 
biopsy from a small nodule [4]. Furthermore, FNAB diagnosis is doubtful in up to $20 \%$ of cases and then thyroid surgery is still needed to confirm malignancy [5].

It is important to differentiate PTC from benign thyroid nodule early enough to avoid an advanced disease course. Therefore, non-invasive biomarkers of PTC are needed [6]. The European Thyroid Association recommends investigating BRAF, RET/PTC, PAX8/PPARG, RAS mutations, TERT promotor and TP53 in case of uncertainty about further clinical action depending on Bethesda classes [6]. Further miRNA investigations are encouraged in the same guidelines, as these molecules demonstrate a potential value in PTC diagnostics and follow up [6].

miRNAs are endogenous non-coding RNA molecules (19-25 nucleotides in length) identified as post-transcriptional negative regulators of gene expression by attaching to the $3^{\prime}$ untranslated region of target mRNAs in the cytoplasm $[7,8]$. miRNAs have been shown to be involved in fundamental biological processes, including metabolism, cell life cycles, tissue differentiation, embryogenesis and organogenesis functions such as cell proliferation and apoptosis, proving their relevance as regulators for oncogenes and tumor suppressor genes [7,9]. Extensive efforts have been made in determining miRNA expression changes in different diseases and cancer types [10]. Tissue and bioliquid (e.g., plasma, serum) miRNA is highly stable [11]. The fact that specific miRNAs are released from tissues into the circulation with the development of disease encourages further studies on the detection of non-invasive biomarkers [11]. Functions of circulating miRNAs are being investigated and hormone-like activity of circulating miRNAs at long distances has been recognized in recent years [12]. However, identification of specific roles of circulating miRNAs, understanding their implication in specific pathways and finding the most sensitive and specific miRNAs is still challenging [13].

It is already known that miR-146b, miR-21, miR-221, miR-222, miR-181b are dysregulated in PTC. These molecules showed potential as biomarkers in PTC tissue and plasma/serum studies [14-23]. It was also demonstrated that downregulation of miR-181b inhibits proliferation and promotes apoptosis in thyroid cancer TPC1 cells, making this miRNA a possible target for PTC treatment [24]. Moreover, miR-181b was also found to be upregulated in PTC tissue samples [25]. miR-21 was found to be overexpressed in PTC compared to healthy thyroid tissue [20], as well as in recurrent PTC compared to non-recurrent PTC $[18,20]$. This miRNA has diagnostic value in head and neck cancer as it is released into the bloodstream [26]. miRNA-21 promotes cell proliferation and invasion via the VHL/PI3K/AKT pathway [27]. miRNA-222 and miRNA-221 also have potential to become biomarkers of PTC. The putative targets for miRNA-222 and -221 are the p27/kip1 and p57/kip2 genes, which affect cell cycle regulation and cancer inhibition [28]. Increased expression of these miRNAs results in downregulation of these genes, which reduces genome instability and cell proliferation [28]. The many effects of miR-146b seen in PTC cells may indicate the significance of this regulatory molecule in the diagnosis and prognosis of PTC [29]. miR-146b was found to increase cell proliferation activity and inhibit cell cycle arrest by downregulating SMAD4 [30]. Moreover, it promotes migration, invasion and epithelial-to-mesenchymal transition by downregulating ZNRF3 [31] and increases cell proliferation by downregulating IRAK1 [32].

The aim of our study was to analyze the expression of five miRNA molecules (miR-21; miR-221; miR-222; miR-146b; miR-181b) in plasma samples and evaluate the differences in patients with PTC, benign nodules and healthy controls to identify the potential biomarkers of PTC for non-invasive diagnostics.

\section{Results}

\subsection{Characteristics of the Study Groups}

Forty-nine patients with papillary thyroid carcinoma (PTC), 23 with nodular goiter (NG) and 57 healthy controls (HC) participated in the study. The mean age of PTC patients was $47.86 \pm 12.1$, that of NG patients was $50.09 \pm 19.3$ and that of HC was $45.43 \pm 12.98(p>0.05)$. 
In the PTC group, there were 8 male patients $(16.32 \%)$ and 41 female patients $(83.68 \%)$, while in the NG group, 1 patient (4.2\%) was male and 22 patients $(95.7 \%)$ were female and in the HC group, 13 participants (22.8\%) were male and 44 participants $(77.19 \%)$ were female $(p>0.05)$.

Among the PTC patients, 8 (16.32\%) had the classical variant of PTC, 7 (14.29\%) had the follicular variant of PTC, 12 (24.48\%) had the diffuse sclerosing variant of PTC and $22(44.89 \%)$ had microcarcinoma. PTC tumor sizes were distributed as follows: 19 (38.87\%)-T1a, $5(10.2 \%)-\mathrm{T} 1 \mathrm{~b}, 3(6.12 \%)-\mathrm{T} 2,22$ (44.89\%)-T3. Twelve (24.49\%) participants with PTC had lymph node metastases. Multifocality was observed in $14(28.57 \%)$, infiltrative growth in $35(71.42 \%)$, capsule overgrowth in $20(40.81 \%)$, soft tissue infiltration in $8(16.32 \%)$ and lymphovascular invasion in $22(44.89 \%)$ of the PTC patients.

\section{2. miRNA Expression Analysis from the The Cancer Genome Atlas (TCGA) Database}

Webtool miR-TV [33] was used for the evaluation of miRNA expression from the TCGA-Thyroid cancer (THCA) project data. Normal vs. tumor sample comparison showed significant upregulation of miR-146b, miR-222, miR-221, miR-21 and miR-181b in primary tumors (Figure 1).
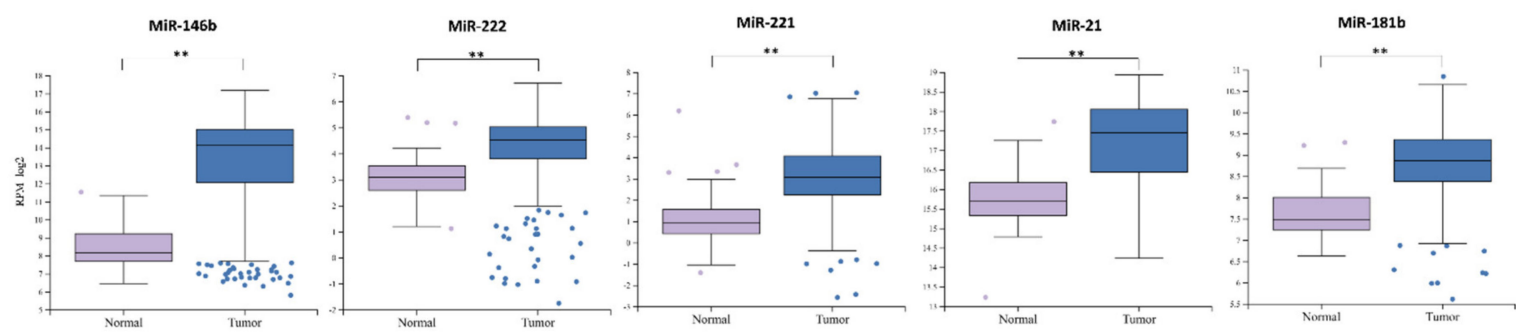

Figure 1. The comparison of miRNA expression between normal and cancerous tissue groups. The box squares represent the data within 25 and 75 percentiles, the line in the middle shows the median, the outliers are shown as dots. ${ }^{* *} p<0.0001$. A total of 565 cases analyzed (normal $n=59$, tumor $n=506$ ).

miRNA-Seq data obtained from the TCGA-THCA repository with additional filters for disease type, prior malignancy/treatment, race and ethnicity were used for a more accurate analysis. Only patients diagnosed with adenocarcinoma without prior malignancy or treatment were included. To obtain data resembling the Lithuanian population, white race with not Hispanic or Latino ethnicity was selected, resulting in 186 primary tumors and 31 solid normal tissue sample data. The significant upregulation pattern of miR-146b, miR-222, miR-221, miR-21 and miR-181b in primary tumors remain clear after additional data filtration (Figure 2).
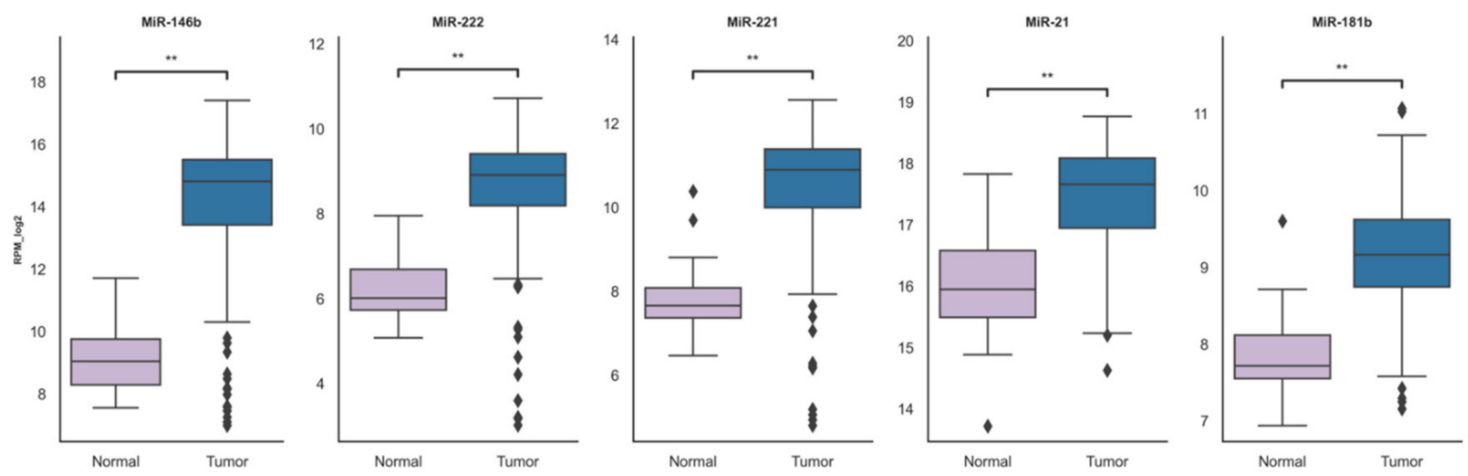

Figure 2. The filtered data comparison of miRNA expression between normal and cancerous tissue groups. The box squares represent the data within 25 and 75 percentiles, line in the middle shows the median, the outliers are shown as diamonds. ${ }^{* *} p<0.0001$. A total of 207 cases analyzed (normal $n=31$, tumor $n=186)$.

To get the results that represent our study cohort even more, we selected to only analyze patients with data for both tumor and normal tissue adjacent to the tumor, resulting in 31 paired samples in 
each group. The upregulation of analyzed microRNAs in primary tumors remained consistent with the prior TCGA data analysis (Figure 3).
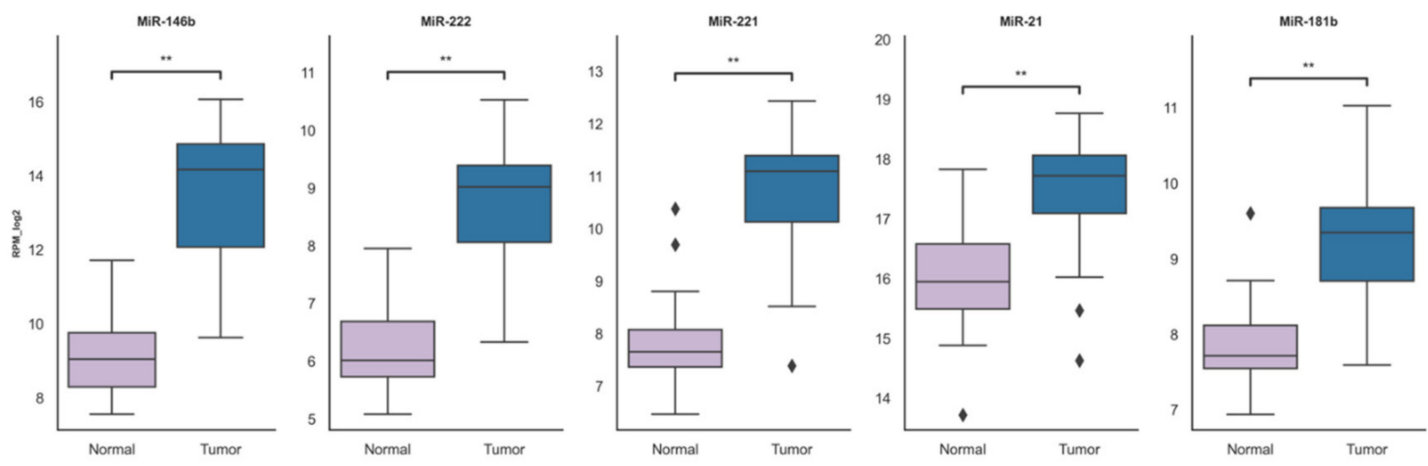

Figure 3. The comparison of miRNA expression between tumor and normal tissue adjacent to the tumor (normal) groups. The box squares represent the data within 25 and 75 percentiles, the line in the middle shows the median, the outliers are shown as diamonds. ${ }^{* *} p<0.0001$. A total of 31 patients were analyzed (paired tumor and adjacent to the tumor (normal) 31 cases in each group).

\subsection{Plasma miRNA Levels in PTC, NG and HC Groups}

miR-221, miR-222, miR-146b, miR-181b and miR-21 expression was significantly higher in the preoperative PTC group compared to the HC group $(p<0.0001, p=0.002, p<0.001, p<0.001, p<0.001$, respectively) (Appendix A; Table A1). Only miRNA-222 expression was significantly higher in PTC patients compared to the NG group $(p=0.004)$. The expression of other investigated miRNAs did not differ significantly between PTC and NG groups (Table A2). Expression of miR-221, miR-21, miR-146b and miR-181b was significantly higher in the NG group compared to the HC ( $p=0.02, p=0.008$, $p=0.033$ and $p=0.003$, respectively) (Figure 4; Table A3).

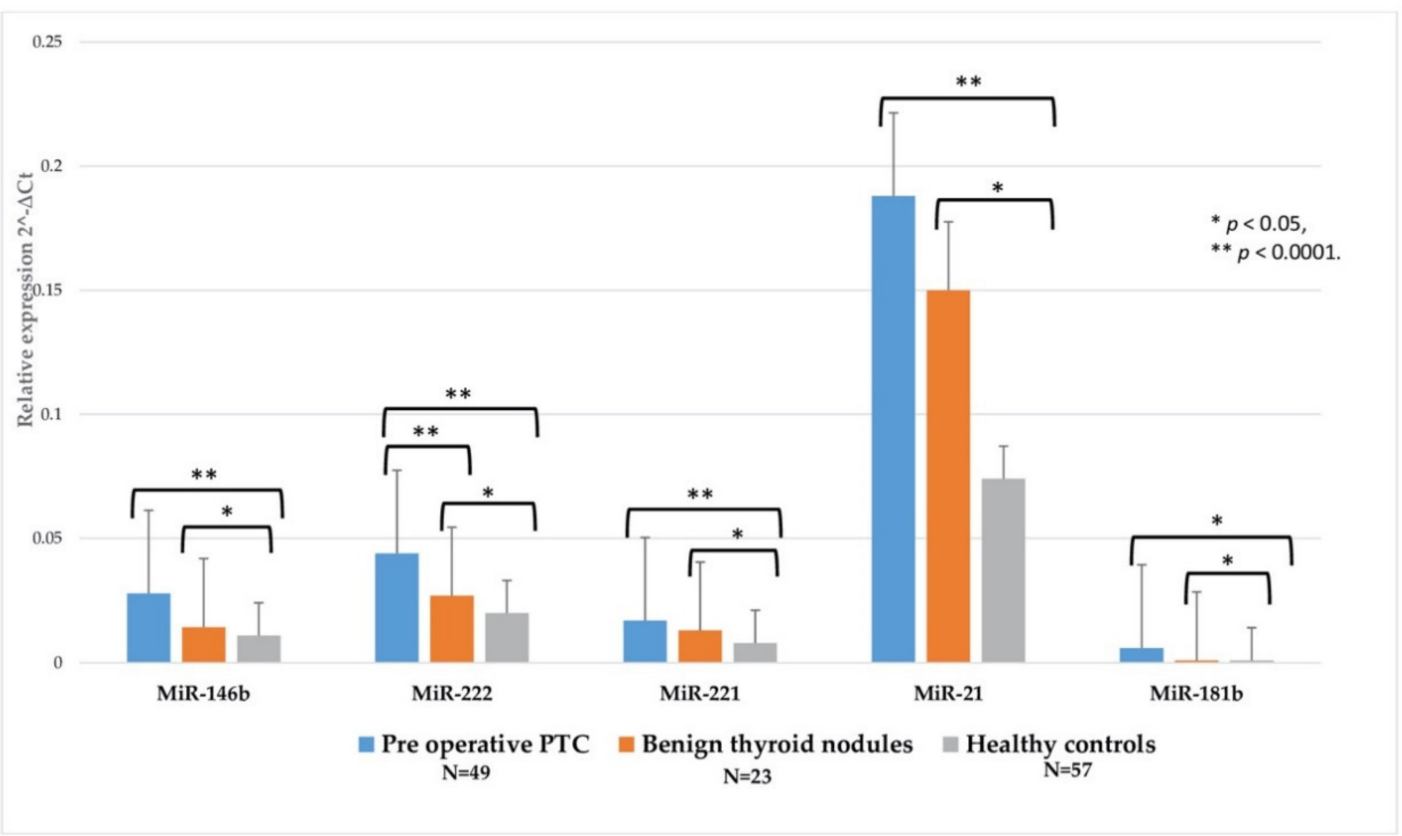

Figure 4. The comparison of plasma miRNA expression between papillary thyroid cancer (PTC), nodular goiter patients and healthy control groups. All data are presented as the mean \pm SD. ${ }^{*} p<0.05$, ** $p<0.0001$. 


\subsection{Plasma miRNA Expression in PTC Patients Before and After Surgery}

Plasma miR-146b, miR-222, miR-21, miR-221 and miR-181b expression after surgery was evaluated depending on the extent of surgery (hemi thyroidectomy or total thyroidectomy). In a group of PTC patients who underwent total thyroidectomy, the expression of miR-146b, miR-21, miR-221 and miR-181b in plasma was significantly lower after surgery $(p=0.03 ; 0.004 ; 0.001 ; 0.038$, respectively) (Table 1). Only miR-221 showed significantly lower plasma expression after hemi thyroidectomy (Table 2).

Table 1. Plasma miRNA levels in papillary thyroid cancer (PTC) patients before and after total thyroidectomy.

\begin{tabular}{|c|c|c|c|c|}
\hline \multirow[b]{2}{*}{$\operatorname{miRNA}$} & \multicolumn{2}{|c|}{ Relative Expression $2^{\wedge}-\Delta \mathrm{Ct}: \mathrm{MEAN} \pm \mathrm{SD}$} & \multirow{2}{*}{ Fold Change } & \multirow{2}{*}{$p$ Value } \\
\hline & $\begin{array}{l}\text { Pre-Operative PTC } \\
(n=30)\end{array}$ & $\begin{array}{c}\text { Post-Operative PTC } \\
(n=30)\end{array}$ & & \\
\hline $146 \mathrm{~b}$ & $0.029 \pm 0.03$ & $0.013 \pm 0.01$ & 1.30 & 0.03 \\
\hline 21 & $0.18 \pm 0.16$ & $0.08 \pm 0.062$ & 1.48 & 0.004 \\
\hline 222 & $0.04 \pm 0.024$ & $0.027 \pm 0.02$ & 1.32 & 0.071 \\
\hline 221 & $0.018 \pm 0.013$ & $0.009 \pm 0.007$ & 1.39 & 0.001 \\
\hline $181 b$ & $0.002 \pm 0.005$ & $0.0006 \pm 0.001$ & 1.23 & 0.038 \\
\hline
\end{tabular}

Table 2. Plasma miRNA expression in papillary thyroid cancer (PTC) patients before and after hemi thyroidectomy.

\begin{tabular}{ccccc}
\hline \multirow{2}{*}{ miRNA } & \multicolumn{2}{c}{ Relative expression $\mathbf{2}^{\wedge}-\Delta$ Ct: MEAN \pm SD } & Fold Change & $p$ Value \\
\cline { 2 - 3 } & $\begin{array}{c}\text { Pre-Operative PTC } \\
(\boldsymbol{n}=7)\end{array}$ & $\begin{array}{c}\text { Post-Operative PTC } \\
(\boldsymbol{n}=\mathbf{7})\end{array}$ & & \\
\hline $146 \mathrm{~b}$ & $0.034 \pm 0.032$ & $0.028 \pm 0.033$ & 1.37 & 0.854 \\
\hline 21 & $0.329 \pm 0.231$ & $0.175 \pm 0.237$ & 4.74 & 0.96 \\
\hline 222 & $0.058 \pm 0.038$ & $0.049 \pm 0.019$ & 1.51 & 0.34 \\
\hline 221 & $0.022 \pm 0.016$ & $0.008 \pm 0.001$ & 2.02 & 0.036 \\
\hline $181 \mathrm{~b}$ & $0.008 \pm 0.012$ & $0.0004 \pm 0.0004$ & 10.26 & 0.063 \\
\hline
\end{tabular}

\subsection{Plasma miRNA Expression in Relation to the Clinicopathological PTC Features}

We analyzed plasma miRNA expression in relation to the clinicopathological PTC features. Plasma expression of miR-222 was found to be higher in multifocal PTC compared to unifocal PTC ( $p=0.024)$ (Table 3). The tendency of miR-181b overexpression in PTC with lymphovascular invasion was observed but no statistically significant relation was found $(p=0.076)$.

To evaluate the diagnostic value of circulating miR-146b, miR-222, miR-21, miR-221 and miR-181b, ROC (receiver operating characteristic) curve analysis was performed. All five miRNAs had statistically significant satisfactory or good diagnostic values to differentiate PTC patients from healthy controls (Figure 5A,C,E,G,J; Appendix B; Tables A4 and A5). miR-221 had the highest AUC of 0.792 (95\% $C I=0.708-0.877$ ), with $73.5 \%$ sensitivity and $73.7 \%$ specificity at the cutoff value of 0.0104 (Figure $5 G$ ). 
Table 3. Clinicopathological features of papillary thyroid cancer (PTC) and relative expression of miR $(-146 b,-221,-21,-222,-181 b)$ in plasma samples.

\begin{tabular}{|c|c|c|c|c|c|}
\hline \multirow[b]{2}{*}{ PTC Clinicopathological Feature } & \multicolumn{5}{|c|}{ Relative Expression $2^{\wedge}-\Delta \mathrm{Ct}$ : $\mathrm{MEAN} \pm \mathrm{SD}$} \\
\hline & $\operatorname{miR}-146 b$ & $\operatorname{miR}-21$ & $\operatorname{miR}-221$ & miR-222 & $\operatorname{miR}-181 b$ \\
\hline \multicolumn{6}{|l|}{ Age } \\
\hline$<55$ years $(n=30 ; 61,2 \%)$ & $0.029 \pm 0.03$ & $0.191 \pm 0.158$ & $0.016 \pm 0.001$ & $0.044 \pm 0.028$ & $0.003 \pm 0.007$ \\
\hline$\geq$ 55years $(n=19 ; 38,8 \%)$ & $0.026 \pm 0.021$ & $0.183 \pm 0.161$ & $0.024 \pm 0.015$ & $0.043 \pm 0.027$ & $0.002 \pm 0.006$ \\
\hline$p$ & 0.967 & 0.853 & 0.361 & 0.864 & 0.967 \\
\hline \multicolumn{6}{|l|}{ Gender } \\
\hline Male $(n=8 ; 16,3 \%)$ & $0.026 \pm 0.019$ & $0.155 \pm 0.142$ & $0.022 \pm 0.013$ & $0.043 \pm 0.018$ & $0.008 \pm 0.012$ \\
\hline Female $(n=41 ; 83,7 \%)$ & $0.028 \pm 0.028$ & $0.194 \pm 0.163$ & $0.016 \pm 0.012$ & $0.044 \pm 0.029$ & $0.002 \pm 0.005$ \\
\hline$p$ & 0.781 & 0.401 & 0.167 & 0.989 & 0.193 \\
\hline \multicolumn{6}{|l|}{ Multifocality } \\
\hline Single $(n=14 ; 28,6 \%)$ & $0.025 \pm 0.027$ & $0.164 \pm 0.138$ & $0.017 \pm 0.014$ & $0.038 \pm 0.023$ & $0.003 \pm 0.007$ \\
\hline Multiple $(\geq 2)(n=35 ; 71,4 \%)$ & $0.036 \pm 0.027$ & $0.250 \pm 0.192$ & $0.017 \pm 0.006$ & $0.059 \pm 0.032$ & $0.001 \pm 0.002$ \\
\hline$p$ & 0.144 & 0.153 & 0.314 & 0.024 & 0.691 \\
\hline \multicolumn{6}{|l|}{ Extrathyroidal extension } \\
\hline Yes $(n=35 ; 71,4 \%)$ & $0.029 \pm 0.03$ & $0.194 \pm 0.174$ & $0.018 \pm 0.012$ & $0.045 \pm 0.029$ & $0.003 \pm 0.006$ \\
\hline No $(n=14 ; 28,6)$ & $0.024 \pm 0.02$ & $0.172 \pm 0.12$ & $0.016 \pm 0.011$ & $0.044 \pm 0.021$ & $0.003 \pm 0.006$ \\
\hline$p$ & 0.842 & 0.833 & 0.400 & 0.765 & 0.535 \\
\hline \multicolumn{6}{|l|}{ Lymphovascular invasion } \\
\hline Yes $(n=22 ; 44,9 \%)$ & $0.03 \pm 0.03$ & $0.180 \pm 0.142$ & $0.017 \pm 0.014$ & $0.054 \pm 0.031$ & $0.004 \pm 0.007$ \\
\hline No $(n=27 ; 55,1 \%)$ & $0.03 \pm 0.03$ & $0.201 \pm 0.194$ & $0.017 \pm 0.011$ & $0.041 \pm 0.023$ & $0.002 \pm 0.006$ \\
\hline$p$ & 0.593 & 0.898 & 0.608 & 0.227 & 0.076 \\
\hline \multicolumn{6}{|l|}{ T (TNM) } \\
\hline T1a, T1b $(n=24 ; 49 \%)$ & $0.033 \pm 0.034$ & $0.226 \pm 0.160$ & $0.021 \pm 0.016$ & $0.047 \pm 0.026$ & $0.005 \pm 0.008$ \\
\hline $\mathrm{T} 2, \mathrm{~T} 3(n=25 ; 51 \%)$ & $0.025 \pm 0.023$ & $0.162 \pm 0.159$ & $0.015 \pm 0.007$ & $0.041 \pm 0.028$ & $0.002 \pm 0.005$ \\
\hline$p$ & 0.327 & 0.071 & 0.343 & 0.312 & 0.090 \\
\hline \multicolumn{6}{|l|}{ Histology } \\
\hline Diffuse sclerosing variant $(n=12 ; 24,5 \%)$ & $0.027 \pm 0.028$ & $0.182 \pm 0.194$ & $0.017 \pm 0.008$ & $0.044 \pm 0.029$ & $0.001 \pm 0.001$ \\
\hline Others $(n=37 ; 75,5 \%)$ & $0.027 \pm 0.028$ & $0.193 \pm 0.152$ & $0.018 \pm 0.014$ & $0.043 \pm 0.004$ & $0.004 \pm 0.008$ \\
\hline$p$ & 0.681 & 0.451 & 0.584 & 0.864 & 0.837 \\
\hline \multicolumn{6}{|l|}{$\begin{array}{l}\text { Lymph node metastases (preoperative } \\
\text { PTC plasma samples) }\end{array}$} \\
\hline Yes $(n=12 ; 24,5 \%)$ & $0.041 \pm 0.043$ & $0.223 \pm 0.2$ & $0.015 \pm 0.013$ & $0.057 \pm 0.034$ & $0.005 \pm 0.011$ \\
\hline No $(n=37 ; 75,5 \%)$ & $0.025 \pm 0.015$ & $0.174 \pm 0.157$ & $0.018 \pm 0.008$ & $0.041 \pm 0.025$ & $0.002 \pm 0.005$ \\
\hline$p$ & 0.276 & 0.555 & 0.618 & 0.358 & 0.618 \\
\hline
\end{tabular}

The expression of miR-21, miR-221, miR-146b and miR-181b did not show statistically significant differences between PTC from NG (Figure 5B, 5F, 5H, 5K; Appendix B; Tables A4 and A5). We calculated expression of miR-221, miR-21, miR-222, miR-146b and miR-181b as one singular entity for ROC analysis. The AUC was $0.579(95 \% \mathrm{CI}=0.518-0.639)(p=0.02)$ in discriminating PTC from NG and the AUC was $0.549(95 \% \mathrm{CI}=0.504-0.594)(p=0.034)$ in discriminating PTC from HC, with no differences seen between the five miRNAs panel.

However, the comparison between PTC patients and those with benign nodules showed that plasma expression of miR-222 had an AUC of 0.711 (95\% CI $=0.587-0.834)$, with $61.2 \%$ sensitivity and $78.3 \%$ specificity at the cutoff value of $0.032(p<0.004)$. This might be useful for differentiating PTC from NG (Figure 5D). 
PTC vs HC

A

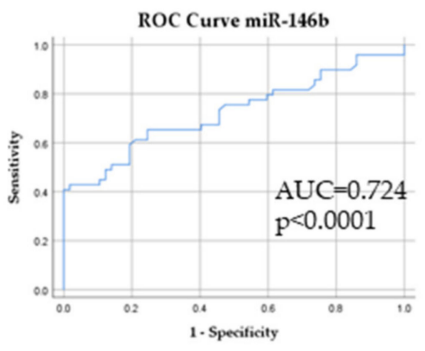

C

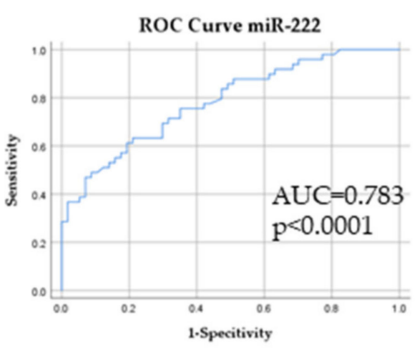

E

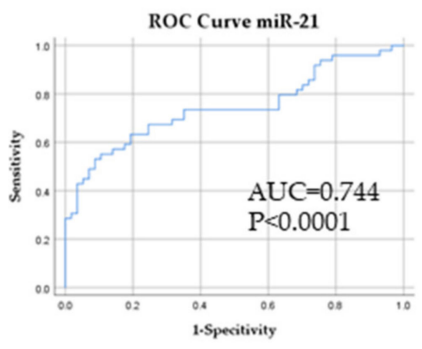

G

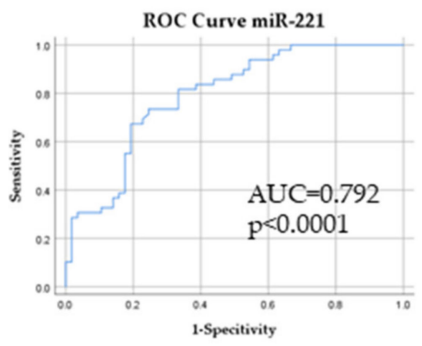

ROC Curve miR-181b

J

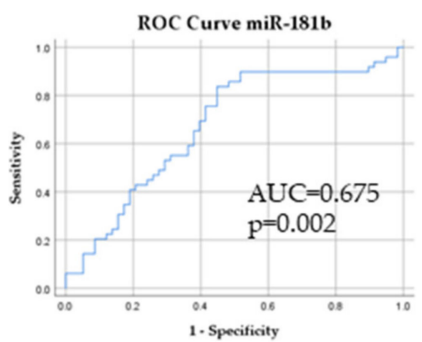

\section{PTC vs NG}

B

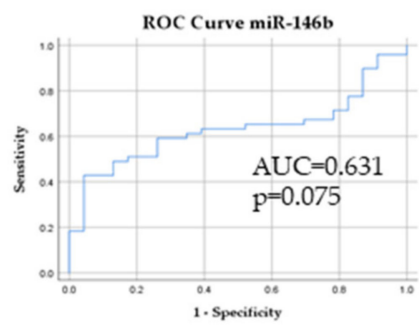

D

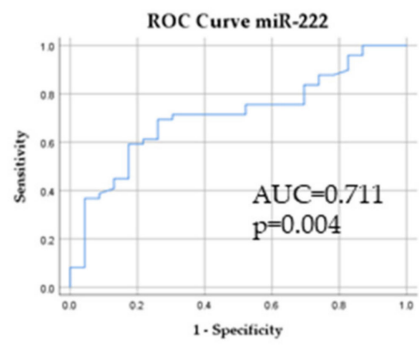

F

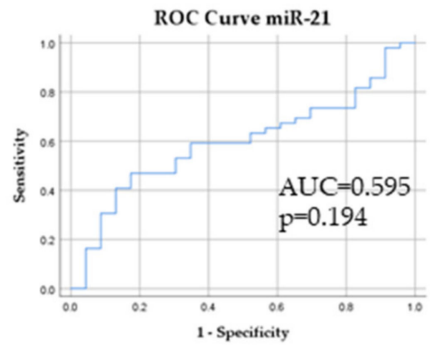

H

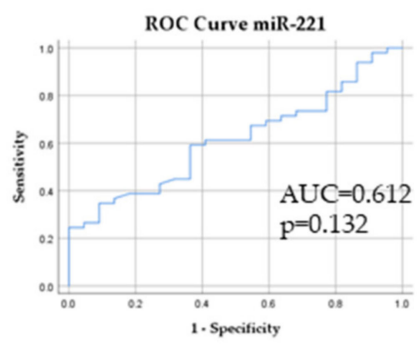

K

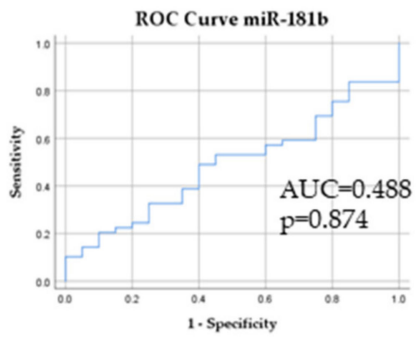

Figure 5. Diagnostic value of miRNAs in discriminating PTC from healthy controls (HC) and nodular goiter (NG). ROC (receiver operating characteristic) curves were used to distinguish the groups. (A) Plasma miR-146b in PTC vs. HC and (B) NG. (C) Plasma miR-222 in PTC vs. HC and (D) NG. (E) Plasma miR-21 in PTC vs. HC and (F) NG. (G) Plasma miR-221 in PTC vs. HC and (H) NG. (J) Plasma miR-181b in PTC vs. HC and (K) NG. ROC, receiver operating characteristic; AUC, area under the curve; PTC, papillary thyroid cancer; NG, nodular goiter; HC, healthy control. 


\subsection{Analysis of miR-222 Targets}

Target prediction analysis indicated four major miR-222 mRNA targets-ARF4 (ADP Ribosylation Factor 4), DCAF12 (DDB1 And CUL4 Associated Factor 12), CDKN1B (Cyclin Dependent Kinase Inhibitor 1B), MYLIP (Myosin Regulatory Light Chain Interacting Protein). The expression of these targets was decreased in tumor tissue, suggesting the silencing function of miR-222 to these genes (Figure 6).
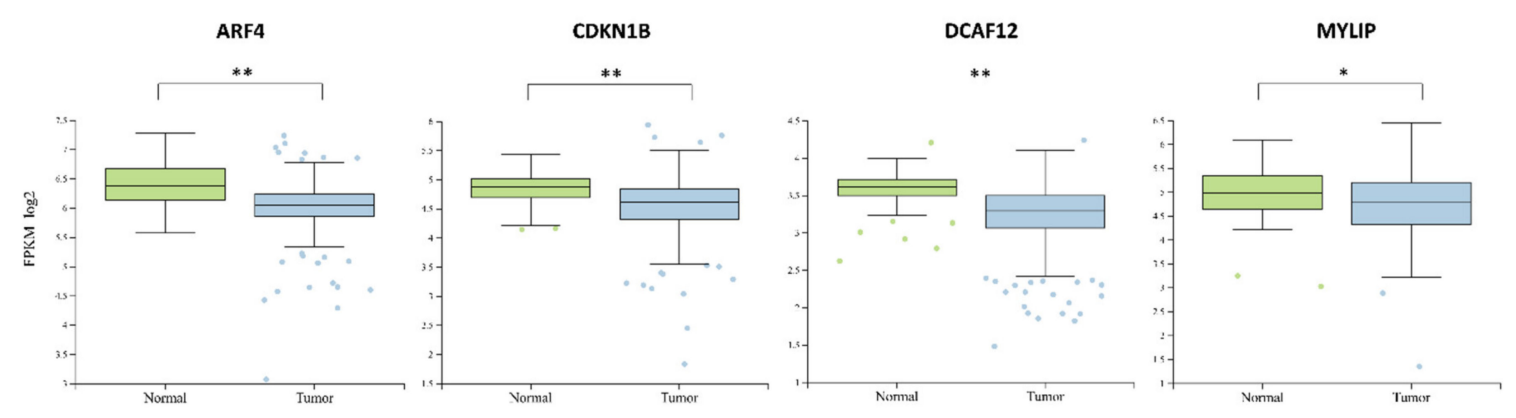

Figure 6. mRNA expression comparison between normal and cancerous tissue groups of the major genes modulated by miR-222. The box squares represent the data within 25 and 75 percentiles, line in the middle shows the median, the outliers are shown as dots. ${ }^{*} p<0.05,{ }^{* *} p<0.0001$. A total of 560 cases analyzed (normal $n=58$, tumor $n=502$ ).

\section{Discussion}

In this study, we investigated five miRNAs (miR-146b, miR-21, miR-221, miR-222, miR-181b) as possible non-invasive biomarkers for PTC. We compared their expression profiles in plasma samples of PTC, NG and HC study groups and analyzed their relation to the clinicopathologic characteristics of PTC. We determined a significant overexpression of miR-146, miR-221, miR-222, miR-21 and miR-181b in PTC plasma samples compared to HC. However, only miR-222 showed a significant difference between PTC and NG study groups. In addition, miR-222 expression was associated with PTC multifocality. ROC analyses indicated that all five miRNAs had statistically significant expression changes that could differentiate PTC patients from healthy controls. Moreover, ROC analysis revealed that miR-222 is a possible plasma-derived diagnostic biomarker for distinguishing PTC from NG.

Tumor-derived miRNAs are released into the circulation [34]; therefore, specific types of circulating miRNAs from each organ may have a diagnostic and prognostic role in different types of cancer [35-38]. Circulating miRNAs have been demonstrated to have an impact on cell-cell communication in tumor biology [39]. The expression of circulating miRNAs is usually evaluated in the plasma or serum [11]. Coagulation may affect the spectrum of extracellular miRNA in the blood [40,41]. We chose to analyze miRNA expression in plasma samples because this bioliquid is prevented from clotting $[40,41]$. Certain studies have already shown changes in circulating miRNA expression in PTC patients [42-44]. Our findings suggest that these five miRNAs are overexpressed in PTC and spread from PTC cells to the bloodstream at detectable levels.

Previous studies have demonstrated that miR-146b, miR-221 and miR-222 are the most consistently overexpressed miRNAs in PTC tissue [14,22,45,46]. Moreover, studies that explored miR-146b, miR-222 and miR-221 expression in plasma samples showed their consistent upregulation in PTC compared to the HC group [22,40]. To our best knowledge, miR-181b and miR-21 have not been investigated in plasma as possible biomarkers of PTC, although they have been found to be overexpressed in PTC tissue samples $[14,18,25]$. Furthermore, miR-21 was analyzed in serum samples and showed potential to become a diagnostic and prognostic marker of PTC [42,43]. We found a significant overexpression of plasma miR-222 in PTC compared to NG. Previous studies also revealed an increase in miR-222 expression in PTC tissue samples as well as plasma samples. M.Rezaei et al. [44] analyzed miR-222, miR-146a and miR-181a in PTC and NG plasma samples and demonstrated an overexpression of these 
three miRNAs in the PTC group. Higher expression levels of miR-222 were also observed in PTC patient compared to NG patient serum samples [16]. However, caution must be taken when comparing miRNA data obtained from different sample types [47]. Our findings show that plasma expression of miR-221, miR-21, miR-146b and miR-181b was not statistically significant in PTC compared to NG, although previous studies have shown the potential diagnostic value of miR-146b [40].

If surgery is chosen for patients with thyroid cancer $<1 \mathrm{~cm}$ without extrathyroidal extension and $\mathrm{cN} 0$, the initial surgical procedure should be a thyroid lobectomy, unless there are clear indications to remove the contralateral lobe. For patients with thyroid cancer $>1 \mathrm{~cm}$ and $<4 \mathrm{~cm}$ without extrathyroidal extension and without clinical evidence of any lymph node metastases (cN0), the initial surgical procedure can be either a bilateral procedure (near total or total thyroidectomy) or a unilateral procedure (lobectomy). Thyroid lobectomy alone may be sufficient initial treatment for low-risk papillary and follicular carcinomas. For patients with thyroid cancer $>4 \mathrm{~cm}$ or with gross extrathyroidal extension (clinical T4) or clinically apparent metastatic disease in nodes (clinical N1) or distant sites (clinical M1), the initial surgical procedure should include a near-total or total thyroidectomy [48]. In our study, plasma levels of five miRNAs were measured in 37 PTC patients before and after surgery (30 patients underwent total thyroidectomy, 7 underwent hemi thyroidectomy). We checked if plasma miRNA expression also decreased in the absence of the tumor. The expression levels of miR-221, miR-21, miR-181b and miR-146b were significantly lower after total thyroidectomy compared with the samples before surgery. This suggests that miR-221, miR-21, miR-181b and miR-146b may have prognostic potential in PTC. Only miR-21 showed a significant reduction in its plasma levels after hemi thyroidectomy in PTC patients. This indicates that the prognostic potential of miR-221, miR-222, miR-146b and miR-181b after hemi thyroidectomy is doubtful since no significant decline is observed 4-6 weeks after surgery. Our observations differ from other studies that investigated the levels of specific circulating miRNAs as a marker to monitor the postoperative PTC progression. Reductions of 2.7-fold and 5.1-fold were observed in the plasma levels of miR-222 and miR-146b, respectively, after total thyroidectomy [22]. Zhang et al. evaluated the levels of miR-222, miR-221 and miR-146b via subsequent RT-qPCR during varied postoperative periods in the same patients [16]. The levels of miR-222, miR-221 and miR-146b rapidly decreased 1 month after surgery compared with their preoperative levels in the PTC group. There was no difference in the miR-222, miR-221 and miR-146b expression levels for patients with PTC undergoing hemi thyroidectomy or total thyroidectomy prior and after surgery [16]. Further studies of plasma miRNA expression after surgery with more subjects and a longer follow-up period would reveal prognostic value of these miRNAs to PTC patients.

As there is a clear association between miRNA expression and the clinicopathological features of PTC [20,49-52], our study revealed higher expression of miR-222 in plasma samples of patients with multifocal PTC. In a previous investigation of PTC tissues, associations of miR-221 [16], miR-146b [53], miR-146a [48] overexpression with PTC multifocality were found. Zhang Y. et al. analyzed the levels of circulating miR-222 in relation to PTC multifocality but no significant differences were found [16].

In our study, ROC curves were used to evaluate the diagnostic value of differently expressed miRNAs in PTC, HC and NG groups, which indicated that all five miRNAs showed statistically significant plasma expression changes that were able to differentiate PTC patients from healthy controls. Moreover, ROC curve analysis confirmed that plasma miR-222 might be a reliable marker in discriminating PTC from NG (AUC $=0.711(95 \%$ CI 0.587-0.834), $p=0.004)$. ROC analysis was not used in previous studies that analyzed miRNA expression levels in the plasma of PTC, NG and/or HC. However, plasma miR-146b (AUC $=0.649$ (95\%CI 0.521-1.77)) was shown to be helpful to discriminate benign thyroid lesions from PTC in a study by Lee at al. [40]. Zhang Y et al. [16] proposed using circulating serum miR-222, miR-221 and miR-146b expression as a possible panel for distinguishing PTC from NG (AUC $=0.903(95 \%$ CI 0.85-0.955)). However, the cohorts of these studies were small and therefore further investigations with a larger sample size are required.

For the first time we provided information about plasma expression of miRNA-21 and miRNA-181b in PTC patients. Furthermore, miRNA-222 plasma expression was found to be a promising diagnostic 
marker of PTC. Moreover, our findings suggest that plasma miRNA expression does not change significantly after hemi thyroidectomy and it therefore might be a useful prognostic marker after total thyroidectomy only. It should be noted that we evaluated expression of plasma miRNAs 4-6 weeks after surgery. Longer observational studies might reveal different results. Similar to previous studies, a limitation of our study is the small sample size. Therefore, it is difficult to make firm conclusions and further investigations are needed to confirm our results.

Target prediction analysis indicated four major miR-222 mRNA targets-ARF4, DCAF12, CDKN1B, MYLIP. Downregulation of ARF4 in thyroid cancer results in inefficiency to accumulate radioiodine due to disrupted trafficking of sodium iodide symporter to the plasma membrane [54]. Interestingly, ARF4 is described as an oncogene by promoting breast cancer cell migration and metastasis to the lungs $[55,56]$. Also, ARF4 is reported to be upregulated in Epithelial ovarian cancer as well as in other major cancer tissues $[57,58]$. The combined downregulation of ARF4 and upregulation of miR-222 might indicate its diagnostic specificity in thyroid cancer. DCAF12 is mostly upregulated in various cancers tissues compared to normal ones and only in the adrenal gland, bone, testis and thyroid cancers it is downregulated [58]. This indicates the diagnostic potential of DCAF12 and miR-222 joint expression evaluation in thyroid cancer. $C D K N 1 B$ is associated with cell cycle regulation by regulating its division. Disruption of $C D K N 1 B$ has been reported to evoke tumorigenesis by increased cell proliferation and loss of function [59]. The downregulation of MYLIP is associated with increased tumor migration and metastasis in breast cancer cells [60]. Also, the inhibition of MYLIP downregulation by TUSC8 resulted in suppressed metastasis showing the important role of MYLIP in cancer [61].

The upregulation of miR-146b, miR-222, miR-221, miR-21 and miR-181b were consistent in both the TCGA-THCA dataset and our research cohort. These findings suggest an oncogenic role of these miRNAs in thyroid cancer. As miR-222, miR-181b, miR-146b, miR-21 and miR-222 are overexpressed in PTC tissue, our findings suggest that they circulate in a highly stable, cell-free form in plasma. Our study demonstrated overexpression of these five plasma miRNAs in the PTC group compared to healthy controls, while only miR-222 showed a significant difference between PTC and NG groups and an association with multifocality. Further studies with larger sample sizes are necessary to confirm its relevance as a biomarker for non-invasive diagnostics and prognosis of PTC.

\section{Materials and Methods}

\subsection{Patient Groups}

Patients with PTC, NG and HC were involved in this study. Plasma samples were obtained from patients with PTC ( $n=49)$ who underwent total or hemi thyroidectomy one day before and 4-6 weeks after surgery at the Hospital of Lithuanian University of Health Sciences Kaunas Clinics between 2016 and 2018. Plasma samples from patients with NG were obtained one day before total or hemi thyroidectomy. The HC group $(n=57)$ had no thyroid disease or autoimmune or oncological illness and their family history for thyroid diseases was negative.

PTC and NG patients underwent thyroidectomy and the diagnosis was confirmed histopathologically after surgery. Classification of patients with PTC according to the 8th edition of the AJCC/UICC staging system was used.

The study was approved by the Kaunas Regional Committee of Biomedical Research (Lithuania, approval No. BE-2-44; 2015-12-23). Written informed consent was obtained from each participant of the study after full explanation of the purpose and nature of all procedures used. This study was conducted in accordance with the Declaration of Helsinki.

\subsection{TCGA Database Analysis}

Webtool miR-TV (Taipei, Taiwan) [33] was used for the primary evaluation of miRNAs'and their mRNA targets' expression (targetScan version 7.2; miRDB version 5.0; miRanda, August 2010 release) from the TCGA-Thyroid cancer (THCA) project data (TCGA version 18.0). For filtered data 
evaluation, the newest version of TCGA dataset was used (version 25.0). Comparison performed using the Statannot package (version 0.2.3; https://github.com/webermarcolivier/statannot) with Python3 (version 3.7.3; Amsterdam, The Netherlands).

\subsection{Plasma Samples}

Venous blood was drawn from PTC patients one day before surgery and one month after the surgery and one day before surgery from NG patients. The samples of peripheral blood $(10 \mathrm{~mL})$ were collected into EDTA (BD Vacutainer PPT ${ }^{\mathrm{TM}}$ Plasma Preparation Tube; $13 \times 100 \mathrm{~mm} / 5 \mathrm{~mL}$ ) venipuncture tubes. The blood was then centrifuged at $1900 \times \mathrm{g}$ for $10 \mathrm{~min}$ at $4{ }^{\circ} \mathrm{C}$. The plasma phase then was transferred to a new tube and centrifuged in conical tubes at $16,000 \times g$ for $10 \mathrm{~min}$ at $4{ }^{\circ} \mathrm{C}$. The supernatant was transferred to $1.5 \mathrm{~mL}$ aliquots and stored at $-80^{\circ} \mathrm{C}$ until nucleic acid purification.

\subsection{RNA Extraction}

The miRNA was extracted from $200 \mu \mathrm{L}$ of thawed plasma using a miRNeasy Serum/Plasma Kit (Qiagen, Hilden, Germany) according to the manufacturer's protocol. The Caenorhabditis elegans miRNA-39 (spike-in cel-miR-39-3p) (Qiagen, Hilden, Germany) was used as a synthetic spike-in control for normalization. An equal amount $\left(8 \times 10^{9}\right.$ copies $)$ of $C$. elegans miR-39-3p was added to each serum sample before RNA isolation. The level of hemolysis in the plasma samples was assessed before miRNA extraction. The plasma $(100 \mu \mathrm{L})$ was centrifuged at $1600 \times g$ for 4 min at $4{ }^{\circ} \mathrm{C}$. Oxy-hemoglobin absorbance was measured at $\lambda=414 \mathrm{~nm}$ wavelength using a NanoDrop ND1000 Spectrophotometer (ThermoFisher Scientific, Waltham, MA, USA). The procedure was repeated 3-5 times and the average optical density (OD) was calculated. Plasma samples with $\mathrm{OD}_{414}>0.25$ were disqualified from further analysis.

\subsection{Quantitative Reverse Transcription-Polymerase Chain Reaction}

The expression levels of the miRNA were measured by a quantitative reverse transcription polymerase chain reaction (qRT-PCR) using a TaqMan Small RNA Assay (Applied Biosystems, Foster City, CA, USA) according to the manufacturer's protocol. First complementary DNA (cDNA) was generated from the extracted RNA using specific primers and TaqMan MicroRNA Reverse Transcription Kit (Applied Biosystems, Foster City, CA, USA). The reaction was performed in a volume of $15 \mu \mathrm{L}$ containing $5 \mathrm{ng}$ of RNA, $100 \mathrm{mM}$ of dNTPs, $50 \mathrm{U} / \mu \mathrm{L}$ of MultiScribe reverse transcriptase, $10 \times$ PCR buffer, $5 \times \mathrm{RT}$ primer, $20 \mathrm{U} / \mu \mathrm{L}$ of RNase inhibitor and nuclease free water. The amplification reaction was performed in a thermal cycler (Applied Biosystems, Foster City, CA, USA) using the following cycling profile: $16{ }^{\circ} \mathrm{C}$ for $30 \mathrm{~min}, 42^{\circ} \mathrm{C}$ for $30 \mathrm{~min}$ and $85^{\circ} \mathrm{C}$ for $5 \mathrm{~min}$. The qPCR was performed using specific TaqMan primers and probes. Real-time fluorescence qPCR was performed using the Rotor-Gene 6000 thermal cycler (Corbett Research, Germany). The reaction conditions were as follows: $95^{\circ} \mathrm{C}$ for $10 \mathrm{~min}$, followed by 40 cycles of $95^{\circ} \mathrm{C}$ for $15 \mathrm{~s}, 60^{\circ} \mathrm{C}$ for $60 \mathrm{~s}$. Twenty microliters of reaction mix contained: $10 \mu \mathrm{L}$ of TaqMan Universal PCR Master Mix (Applied Biosystems, Foster City, CA, USA), 20× of Small RNA Assay, $1.33 \mu \mathrm{L}$ of reverse transcription product and nuclease free water. C.elegans miRNA-39 was used as an internal control. The $2-\Delta \Delta \mathrm{Ct}$ method was used to calculate the fold change in miRNA expression between the two groups. The $2-\Delta \mathrm{Ct}$ method was used to calculate the relative expression of miRNAs in every group and the results were plotted in figures to graphically show the difference in miRNA expression between the groups [62].

Author Contributions: Conceptualization, A.Ž. and B.Ž.; methodology, V.S., D.P., D.D.; validation, D.P., A.D. and R.V.; formal analysis, D.P., A.K., M.K., I.G., R.S.; investigation, D.P., A.K., R.K., M.K, A.D., V.Š.; resources, B.Ž., R.V., V.Š.; data curation, A.K., A.D., D.D.; writing—original draft preparation, A.K., M.K., I.G., R.S.; supervision, D.D., A.D., A.Ž., B.Ž.; writing-review and editing, A.D., D.D., D.P., A.Ž., B.Ž.; visualization, A.K., A.D., D.D., I.G., R.S.; project administration, B.Ž., R.V.; funding acquisition, B.Ž., A.Ž. All authors have read and agreed to the published version of the manuscript. 
Funding: This study was supported by the Lithuanian Research Council (Grant-SEN-14/2015 “Investigation of genetic and epigenetic prognostic markers for prediction of clinical course of papillary thyroid cancer in different age groups").

Acknowledgments: The results published here are in part based upon data generated by the TCGA Research Network: https://www.cancer.gov/tcga.

Conflicts of Interest: We declare no conflict of interest.

\section{Abbreviations}

$\begin{array}{ll}\text { PTC } & \text { Papillary thyroid carcinoma } \\ \text { NG } & \text { Nodular goiter } \\ \text { HC } & \text { Healthy control } \\ \text { MiRNA } & \text { Non coding RNA molecule } \\ \text { miR } & \text { Non coding RNA molecule } \\ \text { ARF4 } & \text { ADP Ribosylation Factor 4 } \\ \text { CDKN1B } & \text { Cyclin Dependent Kinase Inhibitor 1B } \\ \text { DCAF12 } & \text { DDB1 And CUL4 Associated Factor 12 } \\ \text { FPKM } & \text { fragments per kilobase of transcript per million mapped reads } \\ \text { mRNA } & \text { messenger RNA } \\ \text { MYLIP } & \text { Myosin Regulatory Light Chain Interacting Protein } \\ \text { RPM } & \text { reads per million mapped reads } \\ \text { TCGA } & \text { The Cancer Genome Atlas } \\ \text { THCA } & \text { thyroid carcinoma }\end{array}$

\section{Appendix A}

Table A1. miRNA expression comparison between papillary thyroid cancer (PTC) patients before surgery and healthy control plasma samples.

\begin{tabular}{cccc}
\hline \multirow{2}{*}{ miRNA } & \multicolumn{2}{c}{ Relative Expression $\mathbf{2}^{\wedge}-\Delta$ Ct: MEAN \pm SD } & \\
\cline { 2 - 3 } & $\begin{array}{c}\text { Healthy Control } \\
(n=57)\end{array}$ & $\begin{array}{c}\text { Pre-Operative PTC } \\
(n=49)\end{array}$ & \\
\hline $146 \mathrm{~b}$ & $0.011 \pm 0.005$ & $0.0279 \pm 0.027$ & $<0.0001$ \\
\hline 21 & $0.074 \pm 0.043$ & $0.188 \pm 0.159$ & $<0.0001$ \\
\hline 222 & $0.021 \pm 0.013$ & $0.044 \pm 0.027$ & $<0.0001$ \\
\hline 221 & $0.008 \pm 0.006$ & $0.017 \pm 0.012$ & $<0.0001$ \\
\hline $181 \mathrm{~b}$ & $0.001 \pm 0.002$ & $0.006 \pm 0.023$ & 0.002 \\
\hline
\end{tabular}

Table A2. miRNA expression comparison between PTC patients before surgery and NG patients' plasma samples.

\begin{tabular}{cccc}
\hline \multirow{2}{*}{ miRNA } & \multicolumn{2}{c}{ Relative Expression $\mathbf{2}^{\wedge}-\Delta$ Ct: MEAN \pm SD } & \\
\cline { 2 - 3 } & $\begin{array}{c}\text { Pre-Operative PTC } \\
(\boldsymbol{n}=\mathbf{4 9 )}\end{array}$ & $\begin{array}{c}\text { Nodular Goiter } \\
(\boldsymbol{n}=\mathbf{2 3})\end{array}$ & \\
\hline $146 \mathrm{~b}$ & $0.0279 \pm 0.027$ & $0.0144 \pm 0.007$ & $p=0.075$ \\
\hline 21 & $0.188 \pm 0.159$ & $0.152 \pm 0.191$ & $p=0.194$ \\
\hline 222 & $0.044 \pm 0.027$ & $0.027 \pm 0.018$ & $p=0.004$ \\
\hline 221 & $0.017 \pm 0.012$ & $0.013 \pm 0.005$ & $p=0.132$ \\
\hline $181 \mathrm{~b}$ & $0.006 \pm 0.023$ & $0.001 \pm 0.001$ & $p=0.874$ \\
\hline
\end{tabular}


Table A3. miRNA expression comparison between nodular goiter patients and healthy control plasma samples.

\begin{tabular}{cccc}
\hline \multirow{2}{*}{ miRNA } & \multicolumn{2}{c}{ Relative Expression $\mathbf{2}^{\wedge}-\Delta$ Ct: MEAN \pm SD } & \multirow{2}{*}{$p$ Value } \\
\cline { 2 - 3 } & Healthy Control (N57) & Nodular Goiter (23) & \\
\hline $146 \mathrm{~b}$ & $0.011 \pm 0.005$ & $0.014 \pm 0.007$ & $p=0.033$ \\
\hline 221 & $0.008 \pm 0.006$ & $0.013 \pm 0.005$ & $p=0.033$ \\
\hline 222 & $0.022 \pm 0.013$ & $0.027 \pm 0.018$ & $p=0.159$ \\
\hline 21 & $0.074 \pm 0.043$ & $0.151 \pm 0.192$ & $p=0.008$ \\
\hline $181 \mathrm{~b}$ & $0.003 \pm 0.007$ & $0.001 \pm 0.001$ & $p=0.003$ \\
\hline
\end{tabular}

\section{Appendix B}

Table A4. ROC curves analysis for plasma miR-146b, miR-21, miR-221, miR-222 and miR-181b to discriminate papillary thyroid cancer patients from healthy control.

\begin{tabular}{|c|c|c|c|c|c|c|c|}
\hline \multirow[b]{2}{*}{ miRNA } & \multirow[b]{2}{*}{ AUC } & \multicolumn{2}{|c|}{$\begin{array}{c}\text { Asymptotic } 95 \% \\
\text { Confidence Interval }\end{array}$} & \multirow{2}{*}{$p$ Value } & \multirow{2}{*}{$\begin{array}{c}\text { Relative } \\
\text { Expression } \\
2^{\wedge}-\Delta \mathrm{Ct}\end{array}$} & \multirow{2}{*}{ Sensitivity } & \multirow{2}{*}{ Specificity } \\
\hline & & $\begin{array}{l}\text { Lower } \\
\text { Bound }\end{array}$ & $\begin{array}{l}\text { Upper } \\
\text { Bound }\end{array}$ & & & & \\
\hline $146 \mathrm{~b}$ & 0.724 & 0.624 & 0.825 & $<0.0001$ & 0.01 & $65.3 \%$ & $68.4 \%$ \\
\hline 21 & 0.744 & 0.646 & 0.842 & $<0.0001$ & 0.08 & $69.4 \%$ & $68.4 \%$ \\
\hline 221 & 0.792 & 0.708 & 0.877 & $<0.0001$ & 0.01 & $73.5 \%$ & $73.7 \%$ \\
\hline 222 & 0.783 & 0.697 & 0.869 & $<0.0001$ & 0.03 & $67.3 \%$ & $70.2 \%$ \\
\hline $181 \mathrm{~b}$ & 0.675 & 0.571 & 0.779 & 0.002 & 0.0004 & $65.3 \%$ & $62.1 \%$ \\
\hline
\end{tabular}

Table A5. ROC curves analysis for plasma miR-146b, miR-21, miR-221, miR-222 and miR-181b to discriminate papillary thyroid cancer from nodular goiter.

\begin{tabular}{|c|c|c|c|c|c|c|c|}
\hline \multirow[b]{2}{*}{ miRNA } & \multirow[b]{2}{*}{ AUC } & \multicolumn{2}{|c|}{$\begin{array}{c}\text { Asymptotic 95\% } \\
\text { Confidence Interval }\end{array}$} & \multirow{2}{*}{$p$ Value } & \multirow{2}{*}{$\begin{array}{c}\text { Relative } \\
\text { Expression } \\
2^{\wedge}-\Delta C t\end{array}$} & \multirow{2}{*}{ Sensitivity } & \multirow{2}{*}{ Specificity } \\
\hline & & $\begin{array}{l}\text { Lower } \\
\text { Bound }\end{array}$ & $\begin{array}{l}\text { Upper } \\
\text { Bound }\end{array}$ & & & & \\
\hline $146 \mathrm{~B}$ & 0.631 & 0.504 & 0.758 & 0.075 & 0.014 & $59.2 \%$ & $69.6 \%$ \\
\hline 21 & 0.595 & 0.461 & 0.730 & 0.194 & 0.105 & $57.1 \%$ & $65.2 \%$ \\
\hline 221 & 0.612 & 0.480 & 0.745 & 0.132 & 0.014 & $55.1 \%$ & $63.6 \%$ \\
\hline 222 & 0.711 & 0.587 & 0.834 & 0.004 & 0.032 & $61.2 \%$ & $78.3 \%$ \\
\hline $181 b$ & 0.488 & 0.347 & 0.628 & 0.874 & 0.001 & $51.0 \%$ & $55.0 \%$ \\
\hline
\end{tabular}

\section{References}

1. Torre, L.A.; Bray, F.; Siegel, R.L.; Ferlay, J.; Lortet-Tieulent, J.; Jemal, A. Global cancer statistics 2012. CA Cancer. J. Clin. 2015, 65, 87-108. [CrossRef] [PubMed]

2. Pelizzo, M.R.; Merante Boschin, I.; Toniato, A.; Pagetta, C.; Casal Ide, E.; Mian, C.; Rubello, D. Diagnosis, treatment, prognostic factors and long-term outcome in papillary thyroidcarcinoma. Minerva Endocrinol. 2008, 33, 359-379. [PubMed]

3. Han, A.P.; Weng, C.H.; Khawaja, H.T.; Nagarajan, N.; Schneider, E.B.; Umbricht, C.B.; Witwer, K.W.; Zeiger, M.A. MicroRNA Expression and Association with Clinicopathologic Features in Papillary Thyroid Cancer: A Systematic Review. Thyroid 2015, 25, 1322-1329. [CrossRef] 
4. Yoon, J.H.; Kim, E.K.; Kwak, J.Y.; Moon, H.J. Effectiveness and limitations of core needle biopsy in the diagnosis of thyroid nodules: Review of current literature. J. Pathol. Transl. Med. 2015, 49, 230-235. [CrossRef]

5. Lewiński, A.; Adamczewski, Z. Papillary thyroid carcinoma: A cancer with an extremely diverse genetic background and prognosis. Pol. Arch. Intern. Med. 2017, 127, 388-389. [CrossRef]

6. Paschke, R.; Cantara, S.; Crescenzi, A.; Jarzab, B.; Musholt, T.J.; Sobrinho Simoes, M. European Thyroid Association Guidelines regarding Thyroid Nodule Molecular Fine-Needle Aspiration Cytology Diagnostics. Eur. Thyroid J. 2017, 6, 115-129. [CrossRef]

7. Zhang, X.; Mao, H.; Lv, Z. MicroRNA role in thyroid cancer pathogenesis. Front Biosci. 2013, 18, 734-739. [CrossRef]

8. Felekkis, K.; Touvana, E.; Stefanou, C.; Deltas, C. microRNAs: A newly described class of encoded molecules that play a role in health and disease. Hippokratia 2010, 14, 236-240. [PubMed]

9. Filipowicz, W.; Bhattacharyya, S.N.; Sonenberg, N. Mechanisms of post-transcriptional regulation by microRNAs: Are the answers in sight? Nat. Rev. Genet. 2008, 9, 102-114. [CrossRef]

10. Mishra, S.; Yadav, T.; Rani, V. Exploring miRNA based approaches in cancer diagnostics and therapeutics. Crit. Rev. Oncol. Hematol. 2016, 98, 12-23. [CrossRef]

11. Sohel, M.M.H. Circulating microRNAs as biomarkers in cancer diagnosis. Life Sci. 2020, $248,117473$. [CrossRef] [PubMed]

12. Pardini, B.; Calin, G.A. MicroRNAs and Long Non-Coding RNAs and Their Hormone-Like Activities in Cancer. Cancers 2019, 11, 378. [CrossRef]

13. Redis, R.S.; Calin, S.; Yang, Y.; You, M.J.; Calin, G.A. Cell-to-cell miRNA transfer: From body homeostasis to therapy. Pharmacol. Ther. 2012, 136, 169-174. [CrossRef]

14. Pamedytyte, D.; Simanaviciene, V.; Dauksiene, D.; Leipute, E.; Zvirbliene, A.; Sarauskas, V.; Dauksa, A.; Verkauskiene, R.; Zilaitiene, B. Association of MicroRNA Expression and BRAFV600E Mutation with Recurrence of Thyroid Cancer. Biomolecules 2020, 10, 625. [CrossRef] [PubMed]

15. Wen, D.Y.; Pan, D.H.; Lin, P.; Mo, Q.Y.; Wei, Y.P.; Luo, Y.H.; Chen, G.; He, Y.; Chen, J.Q.; Yang, H. Downregulation of miR 486-5p in papillary thyroid carcinoma tissue: A study based on microarray and miRNA sequencing. Mol. Med. Rep. 2018, 18, 2631-2642. [CrossRef] [PubMed]

16. Zhang, Y.; Xu, D.; Pan, J.; Yang, Z.; Chen, M.; Han, J.; Zhang, S.; Sun, L.; Qiao, H. Dynamic monitoring of circulating micrornas as a predictive biomarker for the diagnosis and recurrence of papillary thyroid carcinoma. Oncol. Lett. 2017, 13, 4252-4266. [CrossRef] [PubMed]

17. Rosignolo, F.; Sponziello, M.; Giacomelli, L.; Russo, D.; Pecce, V.; Biffoni, M.; Bellantone, R.; Lombardi, C.P.; Lamartina, L.; Grani, G.; et al. Identification of Thyroid-Associated Serum microRNA Profiles and Their Potential Use in Thyroid Cancer Follow-Up. J. Endocr. Soc. 2017, 1, 3-13. [CrossRef]

18. Dai, L.; Wang, Y.; Chen, L. MiR-221, a potential prognostic biomarker for recurrence in papillary thyroid cancer. World J. Surg. Oncol. 2017, 15, 11. [CrossRef]

19. Qiu, Z.; Li, H.; Wang, J.; Sun, C. MiR-146a and miR-146b in the diagnosis and prognosis of papillary thyroid carcinoma. Oncol. Rep. 2017, 38, 2735-2740. [CrossRef]

20. Sondermann, A.; Andreghetto, F.M.; Moulatlet, A.C.; da Silva Victor, E.; de Castro, M.G.; Nunes, F.D.; Brandão, L.G.; Severino, P. MiR-9 and miR-21 as prognostic biomarkers for recurrence in papillary thyroid cancer. Clin. Exp. Metastasis 2013, 2, 521-530. [CrossRef]

21. Guo, Z.; Hardin, H.; Montemayor-Garcia, C.; Asioli, S.; Righi, A.; Maletta, F.; Sapino, A.; Lloyd, R.V. In Situ Hybridization Analysis of miR-146b-5p and miR-21 in Thyroid Nodules: Diagnostic Implications. Endocr. Pathol. 2015, 26, 157-163. [CrossRef] [PubMed]

22. Lee, J.C.; Zhao, J.T.; Clifton-Bligh, R.J.; Gill, A.; Gundara, J.S.; Ip, J.C.; Glover, A.; Sywak, M.S.; Delbridge, L.W.; Robinson, B.G.; et al. MicroRNA-222 and microRNA-146b are tissue and circulating biomarkers of recurrent papillary thyroid cancer. Cancer 2013, 119, 4358-4365. [CrossRef] [PubMed]

23. Yip, L.; Kelly, L.; Shuai, Y.; Armstrong, M.J.; Nikiforov, Y.E.; Carty, S.E.; Nikiforova, M.N. MicroRNA signature distinguishes the degree of aggressiveness of papillary thyroid carcinoma. Ann. Surg. Oncol. 2011, 18, 2035-2041. [CrossRef] [PubMed]

24. Li, D.; Jian, W.; Wei, C.; Song, H.; Gu, Y.; Luo, Y.; Fang, L. Down-regulation of miR-181b promotes apoptosis by targeting CYLD in thyroid papillary cancer. Int. J. Clin. Exp. Pathol. 2014, 7, 7672-7680. [PubMed] 
25. Zarkesh, M.; Zadeh-Vakili, A.; Akbarzadeh, M.; Nozhat, Z.; Fanaei, S.A.; Hedayati, M.; Azizi, F. BRAF V600E mutation and microRNAs are helpful in distinguishing papillary thyroid malignant lesions: Tissues and fine needle aspiration cytology cases. Life Sci. 2019, 223, 166-173. [CrossRef]

26. Hsu, C.M.; Lin, P.M.; Wang, Y.M.; Chen, Z.J.; Lin, S.F.; Yang, M.Y. Circulating miRNA is a novel marker for head and neck squamous cell carcinoma. Tumour Biol. 2012, 33, 1933-1942. [CrossRef]

27. Zang, C.; Sun, J.; Liu, W.; Chu, C.; Jiang, L.; Ge, R. miRNA-21 promotes cell proliferation and invasion via VHL/PI3K/AKT in papillary thyroid carcinoma. Hum. Cell. 2019, 32, 428-436. [CrossRef]

28. Visone, R.; Russo, L.; Pallante, P.; De Martino, I.; Ferraro, A.; Leone, V.; Borbone, E.; Petrocca, F.; Alder, H.; Croce, C.M.; et al. MicroRNAs (miR)-221 and miR-222, both overexpressed in human thyroid papillary carcinomas, regulate p27Kip1 protein levels and cell cycle. Endocr. Relat. Cancer 2007, 3, 791-798. [CrossRef]

29. Chou, C.K.; Yang, K.D.; Chou, F.F.; Huang, C.C.; Lan, Y.W.; Lee, Y.F.; Kang, H.Y.; Liu, R.T. Prognostic implications of miR-146b expression and its functional role in papillary thyroid carcinoma. J. Clin. Endocrinol. Metab. 2013, 2, E196-E205. [CrossRef]

30. Geraldo, M.V.; Yamashita, A.S.; Kimura, E.T. MicroRNA miR-146b-5p regulates signal transduction of TGF- $\beta$ by repressing SMAD4 in thyroid cancer. Oncogene 2012, 31, 1910-1922. [CrossRef]

31. Deng, X.; Wu, B.; Xiao, K.; Kang, J.; Xie, J.; Zhang, X.; Fan, Y. MiR-146b-5p promotes metastasis and induces epithelial-mesenchymal transition in thyroid cancer by targeting ZNRF3. Cell Physiol. Biochem. 2015, 35, 71-82. [CrossRef] [PubMed]

32. Chou, C.K.; Chi, S.Y.; Huang, C.H.; Chou, F.F.; Huang, C.C.; Liu, R.T.; Kang, H.Y. IRAK1, a target of miR-146b, reduces cell aggressiveness of human papillary thyroid carcinoma. J. Clin. Endocrinol. Metab. 2016, 101, 4357-4366. [CrossRef] [PubMed]

33. Pan, C.Y.; Lin, W.C. MiR-TV: An Interactive MicroRNA Target Viewer for MicroRNA and Target Gene Expression Interrogation for Human Cancer Studies. Available online: https://academic.oup.com/database/ article/doi/10.1093/database/baz148/5707334 (accessed on 21 August 2020).

34. Mitchell, P.S.; Parkin, R.K.; Kroh, E.M.; Fritz, B.R.; Wyman, S.K.; Pogosova-Agadjanyan, E.L.; Peterson, A.; Noteboom, J.; O'Briant, K.C.; Allen, A.; et al. Circulating microRNAs as stable blood-based markers for cancer detection. Proc. Natl. Acad. Sci. USA 2008, 105, 10513-10518. [CrossRef] [PubMed]

35. Tsujiura, M.; Ichikawa, D.; Komatsu, S.; Shiozaki, A.; Takeshita, H.; Kosuga, T.; Konishi, H.; Morimura, R.; Deguchi, K.; Fujiwara, H.; et al. Circulating microRNAs in plasma of patients with gastric cancers. Br. J. Cancer 2010, 102, 1174-1179. [CrossRef] [PubMed]

36. Cheng, H.; Zhang, L.; Cogdell, D.E.; Zheng, H.; Schetter, A.J.; Nykter, M.; Harris, C.C.; Chen, K.; Hamilton, S.R.; Zhang, W. Circulating plasma MiR-141 is a novel biomarker for metastatic colon cancer and predicts poor prognosis. PLoS ONE 2011, 6, e17745. [CrossRef]

37. Shen, J.; Liu, Z.; Todd, N.W.; Zhang, H.; Liao, J.; Yu, L.; Guarnera, M.A.; Li, R.; Cai, L.; Zhan, M.; et al. Diagnosis of lung cancer in individuals with solitary pulmonary nodules by plasma microRNA biomarkers. BMC Cancer 2011, 11, 374. [CrossRef]

38. Kroh, E.M.; Parkin, R.K.; Mitchell, P.S.; Tewari, M. Analysis of circulating microRNA biomarkers in plasma and serum using quantitative reverse transcription-PCR (qRT-PCR). Methods 2010, 50, 298-301. [CrossRef]

39. Butz, H.; Patócs, A. MicroRNAs in endocrine tumors. EJIFCC 2019, 30, 146-164. [PubMed]

40. Lee, Y.S.; Lim, Y.S.; Lee, J.S.; Wang, S.G.; Park, H.Y.; Kim, S.Y.; Lee, B.J. Differential expression levels of plasma-derived miR-146b and miR-155 in papillary thyroid cancer. Oral Oncol. 2015, 51, 77-83. [CrossRef]

41. Dufourd, T.; Robil, N.; Mallet, D.; Carcenac, C.; Boulet, S.; Brishoual, S.; Rabois, E.; Houeto, J.L.; de la Grange, P.; Carnicella, S. Plasma or serum? A qualitative study on rodents and humans using high-throughput microRNA sequencing for circulating biomarkers. Biol. Methods Protoc. 2019, 4, bpz006. [CrossRef]

42. Zhang, Y.; Pan, J.; Xu, D.; Yang, Z.; Sun, J.; Sun, L.; Wu, Y.; Qiao, H. Combination of serum microRNAs and ultrasound profile as predictive biomarkers of diagnosis and prognosis for papillary thyroid microcarcinoma. Oncol. Rep. 2018, 40, 3611-3624. [CrossRef] [PubMed]

43. Yoruker, E.E.; Terzioglu, D.; Teksoz, S.; Uslu, F.E.; Gezer, U.; Dalay, N. MicroRNA Expression Profiles in Papillary Thyroid Carcinoma, Benign Thyroid Nodules and Healthy Controls. J. Cancer 2016, 7, 803-809. [CrossRef] [PubMed] 
44. Rezaei, M.; Khamaneh, A.M.; Zarghami, N.; Vosoughi, A.; Hashemzadeh, S. Evaluating pre- and post-operation plasma miRNAs of papillary thyroid carcinoma (PTC) patients in comparison to benign nodules. BMC Cancer 2019, 19, 690. [CrossRef] [PubMed]

45. He, H.; Jazdzewski, K.; Li, W.; Liyanarachchi, S.; Nagy, R.; Volinia, S.; Calin, G.A.; Liu, C.G.; Franssila, K.; Suster, S.; et al. The role of microRNA genes in papillary thyroid carcinoma. Proc. Natl. Acad. Sci. USA 2005, 102, 19075-19080. [CrossRef]

46. Nikiforova, M.N.; Tseng, G.C.; Steward, D.; Diorio, D.; Nikiforov, Y.E. MicroRNA expression profiling of thyroid tumors: Biological significance and diagnostic utility. J. Clin. Endocrinol. Metab. 2008, 93, 1600-1608. [CrossRef]

47. Wang, K.; Yuan, Y.; Cho, J.H.; McClarty, S.; Baxter, D.; Galas, D.J. Comparing the MicroRNA spectrum between serum and plasma. PLoS ONE 2012, 7, e41561. [CrossRef]

48. Haugen, B.R.; Alexander, E.K.; Bible, K.C.; Doherty, G.M.; Mandel, S.J.; Nikiforov, Y.E.; Pacini, F.; Randolph, G.W.; Sawka, A.M.; Schlumberger, M.; et al. 2015 American Thyroid Association Management Guidelines for Adult Patients with Thyroid Nodules and Differentiated Thyroid Cancer: The American Thyroid Association Guidelines Task Force on Thyroid Nodules and Differentiated Thyroid Cancer. Thyroid 2016, 26, 1-133. [CrossRef]

49. Acibucu, F.; Dökmetaś, H.S.; Tutar, Y.; Elagoz, Ş.; Kilicli, F. Correlations between the expression levels of micro-RNA146b, 221, 222 and p27Kip1 protein mRNA and the clinicopathologic parameters in papillary thyroid cancers. Exp. Clin. Endocrinol. Diabetes 2014, 122, 137-143. [CrossRef]

50. Han, P.A.; Kim, H.S.; Cho, S.; Fazeli, R.; Najafian, A.; Khawaja, H.; McAlexander, M.; Dy, B.; Sorensen, M.; Aronova, A.; et al. Association of BRAF V600E Mutation and MicroRNA Expression with Central Lymph Node Metastases in Papillary Thyroid Cancer: A Prospective Study from Four Endocrine Surgery Centers. Thyroid 2016, 4, 532-542. [CrossRef]

51. Yang, Z.; Yuan, Z.; Fan, Y.; Deng, X.; Zheng, Q. Integrated analyses of microRNA and mRNA expression profiles in aggressive papillary thyroid carcinoma. Mol. Med. Rep. 2013, 8, 1353-1358. [CrossRef]

52. Wang, Z.; Zhang, H.; He, L.; Dong, W.; Li, J.; Shan, Z.; Teng, W. Association between the expression of four upregulated miRNAs and extrathyroidal invasion in papillary thyroid carcinoma. Onco Targets Ther. 2013, 6, 281-287. [CrossRef] [PubMed]

53. Sun, M.; Fang, S.; Li, W.; Li, C.; Wang, L.; Wang, F.; Wang, Y. Associations of miR-146a and miR-146b expression and clinical characteristics in papillary thyroid carcinoma. Cancer Biomark. 2015, 15, 33-40. [CrossRef] [PubMed]

54. Fletcher, A.; Read, M.L.; Thornton, C.E.M.; Larner, D.P.; Poole, V.L.; Brookes, K.; Nieto, H.R.; Alshahrani, M.; Thompson, R.J.; Lavery, G.G.; et al. Targeting Novel Sodium Iodide Symporter Interactors ADP-Ribosylation Factor 4 and Valosin-Containing Protein Enhances Radioiodine Uptake. Cancer Res. 2020, 80, 102-115. [CrossRef] [PubMed]

55. Howley, B.V.; Link, L.A.; Grelet, S.; El-Sabban, M.; Howe, P.H. A CREB3-regulated ER-Golgi trafficking signature promotes metastatic progression in breast cancer. Oncogene 2018, 37, 1308-1325. [CrossRef] [PubMed]

56. Jang, S.Y.; Jang, S.W.; Ko, J. Regulation of ADP-ribosylation factor 4 expression by small leucine zipper protein and involvement in breast cancer cell migration. Cancer Lett. 2012, 314, 185-197. [CrossRef] [PubMed]

57. Wu, Q.; Ren, X.; Zhang, Y.; Fu, X.; Li, Y.; Peng, Y.; Xiao, Q.; Li, T.; Ouyang, C.; Hu, Y.; et al. MiR-221-3p targets ARF4 and inhibits the proliferation and migration of epithelial ovarian cancer cells. Biochem. Biophys. Res. Commun. 2018, 497, 1162-1170. [CrossRef] [PubMed]

58. Park, S.J.; Yoon, B.H.; Kim, S.K.; Kim, S.Y. GENT2: An updated gene expression database for normal and tumor tissues. BMC Med. Genomics 2019, 12, 101. [CrossRef]

59. Accardo, G.; Conzo, G.; Esposito, D.; Gambardella, C.; Mazzella, M.; Castaldo, F.; Di Donna, C.; Polistena, A.; Avenia, N.; Colantuoni, V.; et al. Genetics of medullary thyroid cancer: An overview. Int. J. Surg. 2017, 41, S2-S6. [CrossRef]

60. Zhao, L.; Zhao, Y.; He, Y.; Mao, Y. miR-19b promotes breast cancer metastasis through targeting MYLIP and its related cell adhesion molecules. Oncotarget 2017, 8, 64330. [CrossRef] 
61. Zhao, L.; Zhou, Y.; Zhao, Y.; Li, Q.; Zhou, J.; Mao, Y. Long non-coding RNA TUSC8 inhibits breast cancer growth and metastasis via miR-190b-5p/MYLIP axis. Aging 2020, 12, 2974-2991. [CrossRef]

62. Schmittgen, T.D.; Livak, K.J. Analyzing real-time PCR data by the comparative C(T) method. Nat. Protoc. 2008, 3, 1101-1108. [CrossRef] [PubMed]

(C) 2020 by the authors. Licensee MDPI, Basel, Switzerland. This article is an open access article distributed under the terms and conditions of the Creative Commons Attribution (CC BY) license (http://creativecommons.org/licenses/by/4.0/). 